\title{
NILAI MORAL FILM ANIMASI BIG HERO 6 PRODUKSI WALT DISNEY TERHADAP SIKAP KEPEDULIAN SISWA SEKOLAH DASAR
}

\author{
Dhena Rismaya ${ }^{1}$, Husnul Hadi ${ }^{2}$, Mudzanatun ${ }^{3}$ \\ 1,2,3 Pendidikan Guru Sekolah Dasar Universitas PGRI Semarang Semarang, Indonesia \\ e-mail: rismayadhena@gmail.com
}

\begin{abstract}
ABSTRAK
Karakter seorang anak dibentuk tidak lepas dengan adanya nilai-nilai moral. Apabila proses pertumbuhan dan perkembangan anak tidak disertai atau tidak diimbangi dengan penanaman nilai moral tentunya akan berpengaruh terhadap karakternya misalnya sikap kepeduliannya. Dalam membentuk moral anak dapat dilakukan sejak usia dini yaitu dengan memberi tayangan yang mendidik pada anak. Permasalahan penelitian ini yaitu bagaimanakah nilai moral film animasi Big Hero 6 terhadap sikap kepedulian siswa sekolah dasar. Tujuan penelitian ini adalah menganalisis dan mendeskripsikan nilai moral film animasi Big Hero 6 terhadap sikap kepedulian siswa sekolah dasar . Jenis penelitian ini adalah deskriptif kualitatif. Populasi dalam penelitian ini adalah Populasi dalam penelitian ini adalah seluruh siswa SD Negeri Kebonsawahan 02 tahun 2018/2019. Sampel yang diambil adalah 34 siswa kelas III. Data yang diambil dalam penelitian ini adalah pengaruh postif nilai moral film animasi Big Hero 6 untuk siswa kelas III. Metode pengumpulan data yang digunakan adalah wawancara, observasi, angket dan dokumentasi. Berdasarkan analisis data hasil penelitian setelah dideskripsikan, terdapat banyak sikap kepedulian yang tertanam dalam film animasi Big Hero 6. Nilai moral yang terdapat dalam film animasi Big Hero 6 dapat digunakan sebagai contoh teladan dan penanaman sikap kepedulian pada siswa hal ini terbukti dari hasil wawancara, observasi dan hasil analisis angket yang digunakan. Sikap kepedulian tergambar dalam percakapan serta tindakan yang dilakukan oleh para tokoh cerita didalamnya. Nilai-nilai moral yang terkandung dalam fil animasi Big Hero 6 yaitu tolong menolong, kerja sama, rasa hormat, kebijaksanaan, pemberani, rendah hati, dan pantang menyerah.
\end{abstract}

Kata Kunci : Nilai Moral, Peduli, Film Animasi Big Hero 6.

\begin{abstract}
The character of a child is formed because of moral values. If the process of growth and development of children is not accompanied or not balanced with the planting of moral values, of course it will affect their character, for example, their caring attitude. In shaping the moral of children, it can be done from an early age, namely by giving educational shows to children. The problem of this research is how is the moral value of the Big Hero 6 animated film towards the attitude of caring for elementary school students. The purpose of this study was to analyze and describe the moral value of the Big Hero 6 animated film on the attitude of caring for elementary school students. This type of research is qualitative descriptive. The population in this study was the population in this study were all students of SD Negeri Kebonsawahan 02 year 2018/2019. The sample taken was 34 grade III students. The data taken in this study is the positive influence of the moral value of the Big Hero 6 animated film for class III students. Data collection methods used were interviews, observation, questionnaires and documentation. Based on the analysis of research data after being described, there are many caring attitudes embedded in the Big Hero 6 animated film. The moral values contained in the Big Hero 6 animated film can be used as exemplary examples and the cultivation of caring attitudes to students is evident from the results of interviews, observations and the results of the questionnaire analysis used. Concern is reflected in the conversation and actions taken by the characters in it. The moral values contained in the Big Hero 6 animation fil are help, cooperation, respect, wisdom, courage, humility, and never give up.
\end{abstract}

Keywords : Moral Value, Caring, Big Hero 6 Animation Film 


\section{Pendahuluan}

Manusia hidup di dunia ini pasti membutuhkan manusia lain untuk melangsungkan kehidupannya, karena pada dasarnya manusia merupakan makhluk sosial. Menurut Buchari Alma, dkk. makhluk sosial berarti bahwa hidup menyendiri tetapi sebagian besar hidupnya saling ketergantungan, yang pada akhirnya akan tercapai keseimbangan relatif. Maka dari itu, seharusnya manusia memiliki kepedulian sosial terhadap sesama agar tercipta keseimbangan dalam kehidupan (Buchari, 2010: 201).

Darmiyati Zuchdi (2011: 170) menjelaskan bahwa, peduli sosial merupakan sikap dan tindakan yang selalu ingin memberi bantuan kepada masyarakat yang membutuhkan. Berbicara masalah kepedulian sosial maka tak lepas dari kesadaran sosial. Kesadaran sosial merupakan kemampuan untuk memahami arti dari situasi sosial. Hal tersebut sangat tergantung dari bagaimana empati terhadap orang lain.

Kepedulian adalah sikap sosial dengan memperhatikan sesuatu yang terjadi di masyarakat. Tetapi dalam lingkup penelitian ini adalah sekolah maka peduli dapat diartikan sebagai sikap memperhatikan sesuatu yang terjadi di sekolah secara sadar disertai dengan bentuk perilaku baik terhadap lingkungan maupun sosial. Namun seiring perkembangan zaman sikap kepedulian mulai berkurang hal ini dikarenakan oleh banyak faktor seperti pengaruh gaged. Hampir setiap orang memiliki gaged, bahkan sering kita jumpai orang fokus memainkan gaged nya sambil berjalan dengan tidak memperdulikan yang ada di sekitarnya. Tentunya ini sangat memprihatinkan. Hal ini membuat kurangnya rasa peduli pada diri seseorang tersebut. Selain itu tayangan ditelevisi yang tidak mendidik dan waktu tayang yang tidak sesuai membuat seseorang lebih memilih berdiam diri di rumah dan enggan untuk bersosialisai dengan yang lainnya.

Pembentukan moral pada anak dapat dilakukan sejak usia dini. Lickona (2013: 48) mengatakan bahwa orang tua adalah guru pertama seorang anak dalam pendidikan moral. Salah satunya adalah dengan menyajikan tayangan film pada anak yang merupakan salah satu cara orang tua berkomunikasi dengan anak dan secara tidak langsung dapat membantu orang tua memberikan contoh berperilaku yang baik kepada anak lewat film anak yang mendidik. Hal tersebut dapat memberikan pengaruh terhadap perkembangan moral anak karena menimbulkan kebiasaaan. Tayangan bertema anak-anak sangat menunjang dalam pembentukan sikap moral anak yang dimana dapat mendekatkan anak pada nilai -nilai kehidupan anak. Hal itu disebabkan karena anak selalu meniru tingkah laku atau perilaku yang mereka lihat secara langsung atau melalui media elektronik .

Dengan adanya film animasi Big Hero 6 ini diharapkan dapat memberi contoh perilaku yang baik kepada anak-anak melalui tokoh yang diperankan dalam film Big Hero 6 tersebut yang memiliki sifat peduli terhadap sesama. Berdasarkan masalah di atas maka peneliti melakukan penelitian yaitu menganalisis nilai moral pada film animasi Big Hero 6 terhadap sikap kepedulian siswa sekolah dasar.

\section{Metode}

Penelitian ini menggunakan teknik analisis kualitatif. Penelitian ini peneliti menganalisis nilai moral yang terkandung dalam film animasi Big Hero 6 serta sikap kepedulian siswa. Sumber data primer dari penelitian ini yaitu hasil wawancara yang dilakukan dengan kepala sekolah SD Negeri Kebonswahan 02 Juwana, guru kelas III SD Negeri Kebonsawahan 02 Juwana serta, observasi perilaku peserta didik kelas III SD Negeri Kebonsawahan 02 serta pengisian angket. sumber data sekunder dalam penelitian ini yaitu film animasi Big Hero 6 produksi Walt Disney yang diunduh dari bioskopkeren.xyz berupa video disertai dialaog atau percakapannya. Teknik pengumpulan data dalam penelitian ini yaitu: (1) Wawancara, (2) Observasi, (3) Angket, (4) Dokumentasi. Langkah-langkah dalam analisis data yaitu: pengumpulan data, reduksi data, penyajian data dan penarikan kesimpulan. Dalam menganalisis data ini dilakukan tahap-tahap sebagai berikut: (1) Menonton film animasi Big Hero 6 dan melakukan pengamatan pada siswa kelas 3 SD Negeri Kebonswahan 02 Juwana, (2) Menganalisis nilai moral pada film animasi Big Hero 6 
dan sikap kepedulian siswa kelas 3 SD Negeri Kebonswahan 02 Juwana, dan (3) Menyimpulkan hasil analisis nilai moral pada film animasi Big Hero 6 terhadap sikap kepedulian siswa kelas 3 SD Negeri Kebonswahan 02 Juwana.

\section{Hasil dan Pembahasan}

Menurut Yaumi, (2014 : 77) Manusia adalah makhluk sosial yang selalu membutuhkan pihak lain. Seorang manusia tidak akan mungkin tumbuh secara ideal tanpa bantuan dari orang lain. Membantu dan memikirkan kepentingan orang lain adalah suatu tindakan terpuji. Tindakan seperti itulah yang sering disebut dengan peduli atau kepedulian. Kepedulian adalah merasakan kekhawatiran tentang orang lain atau sesuatu. Misalnya ketika melihat teman dalam keadaan susah atau sakit, muncul perasaan yang sama seperti yang dirasakan oleh teman lalu mendapat dorongan untuk merawatnya.

Kemampuan film dalam menampilkan dalam menampilkan realita dalam bentuk audiovisual tersebut juga berpengaruh terhadap penontonnya baik kearah positif maupun negatife melalui gagasan, ide, serta nilai sosial secara utuh. Oleh karena itu film termasuk sebagai salah satu medium perubahan karakteristik dan sikap yang kuat. Salah satu tayangan yang disukai oleh anak-anak adalah film kartun atau animasi . Film animasi disukai anak-anak karena film kartun banyak berisi lelucon dan humor yang seru. Tema dan alur yang diceritakan ringan sehingga mudah diterima dan dimengerti oleh anak-anak, selain itu tampilan film animasi dikemas dengan bagus dan menarik minat anak-anak untuk menontonnya.

Orang tua harus tetap selalu membimbing dan mengarahkkan anak-anak dalam memilih tayangan atau tontonan yang baik dan dapat mendidik. Seperti yang tercantum dalam UU RI No. 20 Tahun 2003 tentang Sistem Pendidikan Nasional pasal 3 yang menyebutkan bahwa pendidikan nasional berfungsi mengembangkan kemampuan dan membentuk watak serta peradaban bangsa yang bermartabat dalam rangka mencerdaskan kehidupan bangsa, bertujuan untuk mengembangkan potensi siswa agar menjadi manusia yang berakhlak mulia, beriman dan bertaqwa kepada Tuhan Yang Maha Esa, berilmu, cakap, kreatif mandiri dan bertanggung jawab.

Data awal yaitu film animasi Big Hero 6 ini dirilis sejak 7 November 2014 oleh Walt Disney Pictures. Big Hero 6 adalah film 3D superhero animasi komputer yang diproduksi oleh Walt Disney Animation Studios, berdasarkan dari tim superhero Marvel Comics dengan nama yang sama. Film ini disutradarai oleh Don Hall, co-direktur Winnie the Pooh, dan Chris Williams, co-direktur Bolt. Ini menjadi film animasi yang ke-54 di Walt Disney Animated Classics series. Di Indonesia, film ini tayang perdana di saluran TV kabel Fox Movies Premium pada bulan Agustus 2015 dalam Bahasa Inggris. Versi Bahasa Indonesia dari film ini ditayangkan perdana di HBO Asia pada tanggal 18 Desember 2016 sebagai salah satu pilihan bahasa, kemudian ditayangkan di RCTI pada tanggal 25 Desember 2016 WIB dan di Global TV pada tanggal 1 Januari 2017. Selain itu terkait dengan sikap kepedulian siswa peneliti menggunakan angket yang harus diisi oleh tiap siswa dengan membagikan kepada siswa kelas 3 SD Negeri Kebonsawahan 02 Juwana.

Film Big Hero 6 tersebut akan ditonton secara tekun, kemudian memperhatikan dengan menganalisis nilai-nilai moral yang terkandung dalam film tersebut. Deskripsi akan dilakukan sinopsis film Big Hero 6, unsur intriksik film beserta bukti gambar dan bukti kalimat yang mencerminkan nilai moral serta hasil analisis tentang sikap kepedulian pada siswa kelas 3 SD Negeri Kebonsawahan 02 Juwana. Film Big Hero 6 merupakan film yang menceritakan tentang Hiro Hamada seorang anak usia 14 tahun yang memiliki keahlian dalam bidang robotik.

1. Sinopsis

Hiro Hamada adalah bocah ahli robotik berumur 14 tahun. Dia menghabiskan kesehariannya bergabung dalam pertarungan robot ilegal. Sejak kedua orang tuanya meninggal karena kecelakaan Hiro tinggal bersama Kakaknya bernama Tadashi Hamada dan Bibi Cass di kota metropolitan San-Fransokyo. Kakak Hiro, Tadashi takut Hiro akan menyia-nyiakan potensinya. Tadashi membawanya ke universitas tempatnya belajar, 
San-Fransokyo Institute of Technology (SFIT), di mana Hiro bertemu dengan temanteman Tadashi. Mereka adalah Go Go Tomago, Fred, Wasabi No-Ginger,dan Honey Lemon. Begitu juga dengan Baymax, robot penjaga kesehatan pribadi yang diciptakan Tadashi. Hiro yang kagum, memutuskan untuk bergabung ke SFIT. Hiro kemudian mempersembahkan projectnya, Microbots untuk bisa masuk ke SFIT. Microbots adalah sekumpulan robot kecil yang dapat bergabung bersama membentuk apapun dalam setiap bayangan pengaturan. Profesor Callaghan, ketua dari program universitas, tertarik dengan project Hiro. Dengan demikian Hiro masuk ke dalam universitas itu. Lalu Alistair Krei yaitu presiden dari Tech Company berusaha untuk membeli ciptaan itu. Tetapi Hiro menolak tawaran tersebut. Kemudian Tadashi mengajak Hiro untuk membicarakan mengenai pengalaman Tadashi bisa masuk SFIT. Tiba-tiba terjadi kebakaran, ketika api mulai membara di universitas atau tempat mempersembahkan project microbotnya tadi, Tadashi masuk ke dalam untuk menyelamatkan Callaghan yang terjebak di dalamnya, namun ledakan terjadi,dan Tadashi pun terbunuh dalam universitas itu. Setelah kematian kakaknya,Hiro menjadi pendiam,dan mengasingkan dirinya dari teman-temannya.

Suatu hari,Hiro tidak sengaja mengaktifkan Baymax, secara bersamaan dia menemukan 1 microbot di saku jaketnya,microbot itu membawa mereka berdua ke satu rumah gudang yang sudah ditinggalkan. Di situ,Hiro menemukan bahwa seseorang telah menggandakan microbots ciptaannya dalam jumlah yang sangat banyak.Kemudian,dia diserang oleh orang bertopeng (Julukannya "Yokai") yang mengendalikan microbots ciptaannya. Mereka meloloskan diri,dan pergi ke kantor polisi. Tidak dapat meyakinkan polisi tentang dirinya yang diserang oleh Yokai, dia memutuskan untuk menangkap orang bertopeng itu. Dia memperbaharui Baymax dengan armor ciptaannya,dan memasangnya chip petarung. Di suatu tempat, Hiro terlibat dalam penyerangan Microbots Yokai bersama Go Go Tomago,Fred,Wasabi,dan Honey Lemon. Mereka segera melarikan diri dengan mobil van milik Wasabi.namun mobil van Wasabi masuk ke laut dan tenggelam, Namun Baymax segera menolong mereka. Kemudian mereka pun melarikan diri ke mansion Fred. Di situ, Hiro memiliki ide membentuk sebuah kumpulan superhero yang terdiri dari Hiro,Honey Lemon,Baymax,Wasabi,Fred,dan Go Go Tomago. Hiro menciptakan armor atau kostum untuk semua temannya,termasuk dirinya sendiri dan Baymax.

Mereka segera mengivestigasi laboratorium lama milik Krei Tech yang dulunya telah dipakai untuk menguji teknologi teleportasi. Saat pengujian teknologi teleportasi ketika pilot tes yang mengendarai kendaraan menuju portal itu,masalah terjadi ketika suatu sistem eroryang menyebabkan pilot itu terjebak di dalamnya. Mulai saat itulah mereka diserang oleh Yokai, setelah pertarungan singkat, Hiro berhasil mencabut topengnya, dan mendapati bahwa orang itu adalah profesor Callaghan, Callaghan telah mencuri Microbots Hiro untuk menyelamatkan dirinya. Mengetahui bahwa Tadashi mati dengan sia-sia. Hiro menyuruh Baymax untuk membunuh Callaghan, tetapi Baymax tidak ingin membunuh Callaghan. Hiro secara kasar membuang chip perawat baymax, dan hanya memasukan chip petarungnya, Baymax langsung menjadi mesin pembunuh dan segera mencoba membunuhnya. Teman-teman Hiro segera mencoba menghentikannya,dan akhirnya Honey Lemon memasukkan kembali chip perawat Baymax,Baymax segera kembali normal,dan Callaghan segera melarikan diri. Hiro marah kepada teman-temannya dan pulang kembali ke rumahnya. Di garasi rumahnya,dia mencoba kembali membuang chip perawatnya,namun tidak bisa. Hiro mengatakan bahwa dengan membunuh Callaghan dapat memuaskan hatinya, untuk menenangkan hatinya,Baymax menampilkan video tentang Tes Tadashi terhadap Baymax, Tadashi baru berhasil pada test ke-84,Hiro mengetahui bahwa membunuh Callaghan bukanlah hal yang diminta Tadashi untuk membalas kematiannya.

Teman-teman Hiro dan dia mengetahui bahwa pilot tes yang terjebak dalam portal itu adalah anak Callaghan yaitu Abigail. Callaghan membalas dendam kepada Alistair Krei yang telah menyebabkan kematian putrinya. Callaghan ingin membunuh Krei dengan melemparnya ke dalam portal yang aktif. Namun rencana itu telah diganggu oleh Hiro dan teman-temannya dengan melumpuhkan sejumlah Microbots Callaghan. Di dalam portal 
yang aktif, Baymax telah mendeteksi tanda hidup dari Abigail, Hiro dan Baymax segera melaju kesana untuk menyelamatkannya.Tapi di jalan keluar mereka, armor Baymax rusak, sehingga satu-satunya cara untuk menyelamatkan Abigail dan Hiro adalah dengan menembakkan rocket fist milik Baymax. Namun, Hiro tidak mau meninggalkannya, tetapi dia harus. Dan akhirnya dia harus meninggalkan Baymax di belakang dengan air mata berlinang. Setelah mereka keluar,portal akhirnya meledak. Abigail segera dilarikan ke rumah sakit, dan Callaghan ditahan polisi.

Suatu hari setelah kejadian itu, Hiro telah menemukan chip perawat Baymax (Yang mengandung semua personalitas Baymax) di rocket fist milik Baymax. Dia kembali membuat Baymax,dan kebahagiaan pun muncul kembali.

2. Unsur Intriksik

a. Tema

Film animasi Big Hero 6 memiliki tema rasa peduli, salah satu yang tercermin dalam film tersebut adalah teman-teman Hiro yang simpati dan empati terhadap Hiro saat hiro kehilangan sang kakak.

b. Tokoh dan Penokohan

1) Hiro, adalah anak yang ahli robot berusia 14 tahun. Dia sedang mengalami masa pubertas. ini adalah masa yang sulit bagi seorang anak dan beberapa remaja sehingga dalam film tersebut Hiro memiliki karakter sikap kasar dan keluguan yang tak terelakkan selain itu dia juga seorang yang optimis dan jenius. Hal ini dibuktikan dengan kemampuan dia menciptakan microbots. "Lihatlah.. akan kuperkenalkan baymax versi 2.0..." (Durasi ke 56:46), "Baymax hancurkan dia..."(Durasi ke 01:10:02) , "Aku sudah hampir menangkapnya kenapa kalian melakukan hal itu?".(Durasi Ke $01: 11: 24)$

2) Baymax, robot tiup yang dibuat oleh Tadashi sebagai asisten medis. Baymax dirancang sebagai robot yang dapat membantu orang. Sehingga dalam film tersebut Bymax memiliki karakter peduli, lucu dan perhatian. Terbukti dari dialog yaitu "kau pasienku, aku ingin membantumu..."(Durasi Ke 40:07).

3) Tadashi, kakak laki-laki Hiro dan pencipta Baymax. Dalam film tersebut Tadashi memiliki karakter ramah, pandai bergaul, peduli, suka menolong, tidak putus asa dan cerdas. Hal ini terbukti bahwa Kakak Tadashi sangat perhatian dengan adiknya Hiro dalam dialog " Aku tak bisa menghalangimu, tapi aku tak kan memebiarkanmu pergi sendirian..."(Durasi ke 07:12), "ini Tadashi Hamada dan ini tes ke 84 projrct robotku..." (Durasi Ke 01:14:00).

4) Fred, penggemar buku komik yang juga merupakan maskot tim di San Fransokyo Institute of Technology. Dalam film tersebut Fred memiliki karakter rendah hati hal ini terbukti dalam scene saat mengajak teman-temannya ke rumah teman-temannya sama sekali tidak menyadari bahwa Fred adalah anak orang kaya, humoris, penyemangat. Terbukti dalam dialog yaitu "Hiro.. Jika aku punya kekuatan super, aku ingin memiliki kemampuan merangkak ke kamera ini dan memelukmu..."(Durasi ke 25:46)

5) Wasabi, seorang siswa atletis tangguh yang berspesialisasi dalam elektromagnetik. Dalam film tersebut Wasabi memiliki karakter bijaksana, humoris, rapi dan teratur. Hal ini terbukti dalam sebuah dialog yaitu "Aku punya sistem, Ada tempat buat semuanya dan semuanya ada tempat..."(08:51). "yang baru saja kau perbuat kami tidak setuju itu"(Durasi ke 01:11:26).

6) Go Go, dalam film tersebut Go Go memiliki karakter yang cerdas, berhati-hati, tegas dan sedikit keras kepala. Terbukti dalam dialog "Aku akan menyelamatkanmu..." (Durasi ke 47:08).

7) Honey Lemon, dalam film tersebut Honey Lemon memiliki karakter yang pekerja keras, penyemangat. Terbukti dalam dialog "Paling tidak kita tahu peralatan kita berfungsi..." (Durasi ke 01:03:05).

8) Robert Callaghan, dalam film tersebut Callagan memiliki karakter pendendam dan licik. Hal ini di buktikan dengan adanya cene bahwa Callagan menyamar sebagai 
Yokai dan ingin membunuh Krei. Terbukti dalam dialog "Tidak, aku dapat bantuan dari microbotmu...berikan topengnya Hiro!..."(Durasi ke 01:09:42)

9) Alistair Krei, seorang pengusaha perintis, ahli teknologi, dan CEO Krei Tech dan selalu mencari hal besar berikutnya. Dalam flm tersebut Krei memiliki karakter mampu melihat peluang dan cerdas. Terbukti dalam dialog "Aku ingin microbotsmu di kembangkan di Krei Tech..." (Durasi ke 20:14)

10) Cass, dalam film tersebut Cass sebagai bibi hero memiliki karakter yang peduli kepada Hiro selain itu bibi Cass juga seorang yang penyayang hal ini dibuktikan dalam dialog bibi cass yaitu "Selama 10 tahun bibi berusaha keras membesarkan kalian..."(Durasi ke 06:02).

11) Abigail, putri Profesor Callaghan dan seorang pilot percobaan untuk Krei Tech. Dalam film tersebut Abigail memiliki karakter sesorang perempuan yang pemberani hal ini dibuktikan dengan salah satu scene Abigail berani masuk ke pesawat kapsul untuk melakukan teleportasi. Terbukti dalam dialog yaitu "Kita sudah mengundang mereka, mari berikan pertunjukan...”(Durasi ke 01:05:54).

c. Alur

Alur dalam cerita ini adalah alur maju dikenalkan secara runtut yaitu dengan mengenalkan salah satu contoh masalah yaitu Hiro mengetahui bahwa ada yang mencuri dan memproduksi microbotsnya dengan sekala besar tanpa sepengetahuannya. Dan diakhiri dengan kerjasama keenam pahlawan untuk menghentikan kejahatan yang dilaukan oleh Prof Callagan.

d. Latar

Latar tempat

Tabel 1. Latar Tempat dan Bukti Gambar

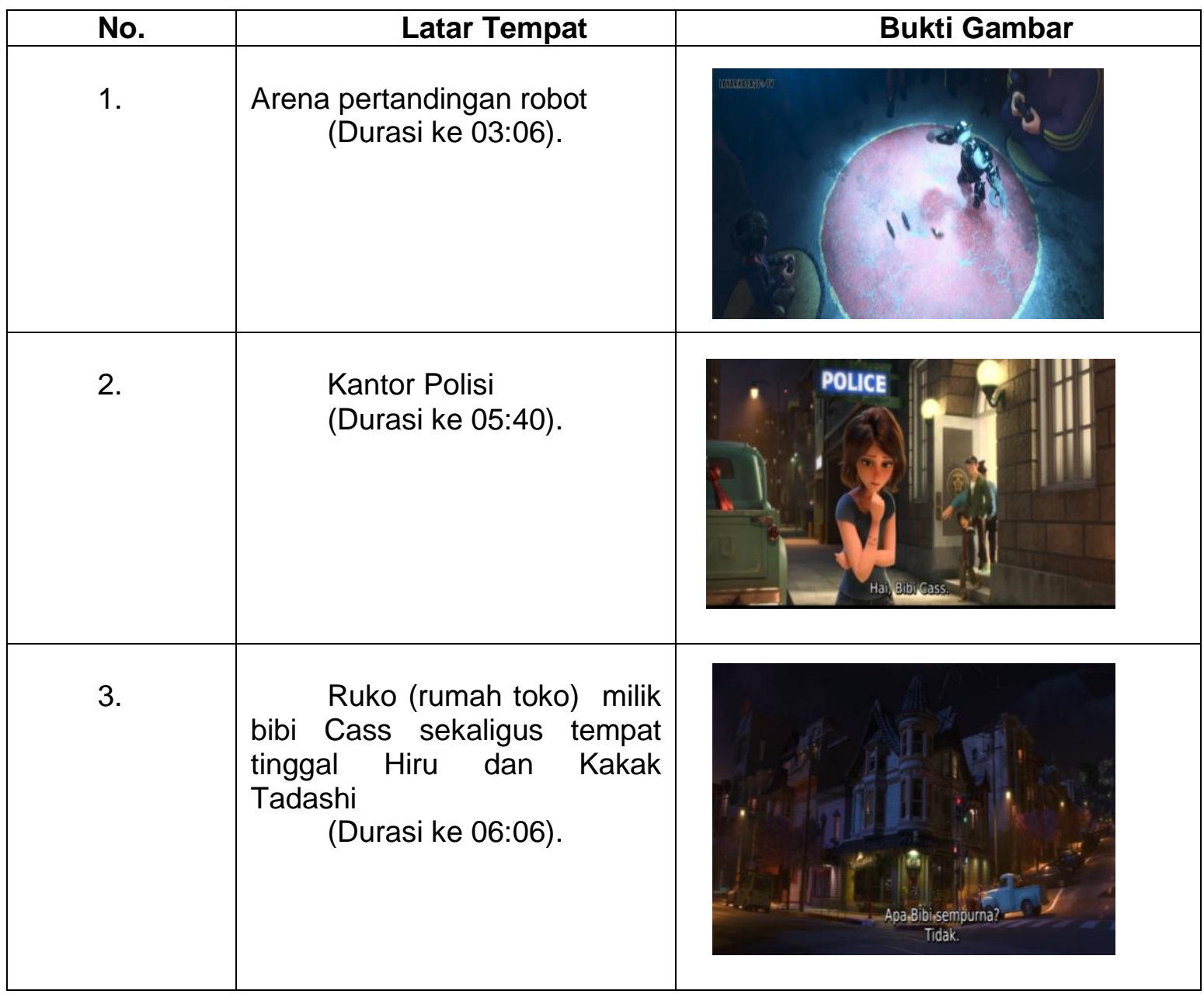




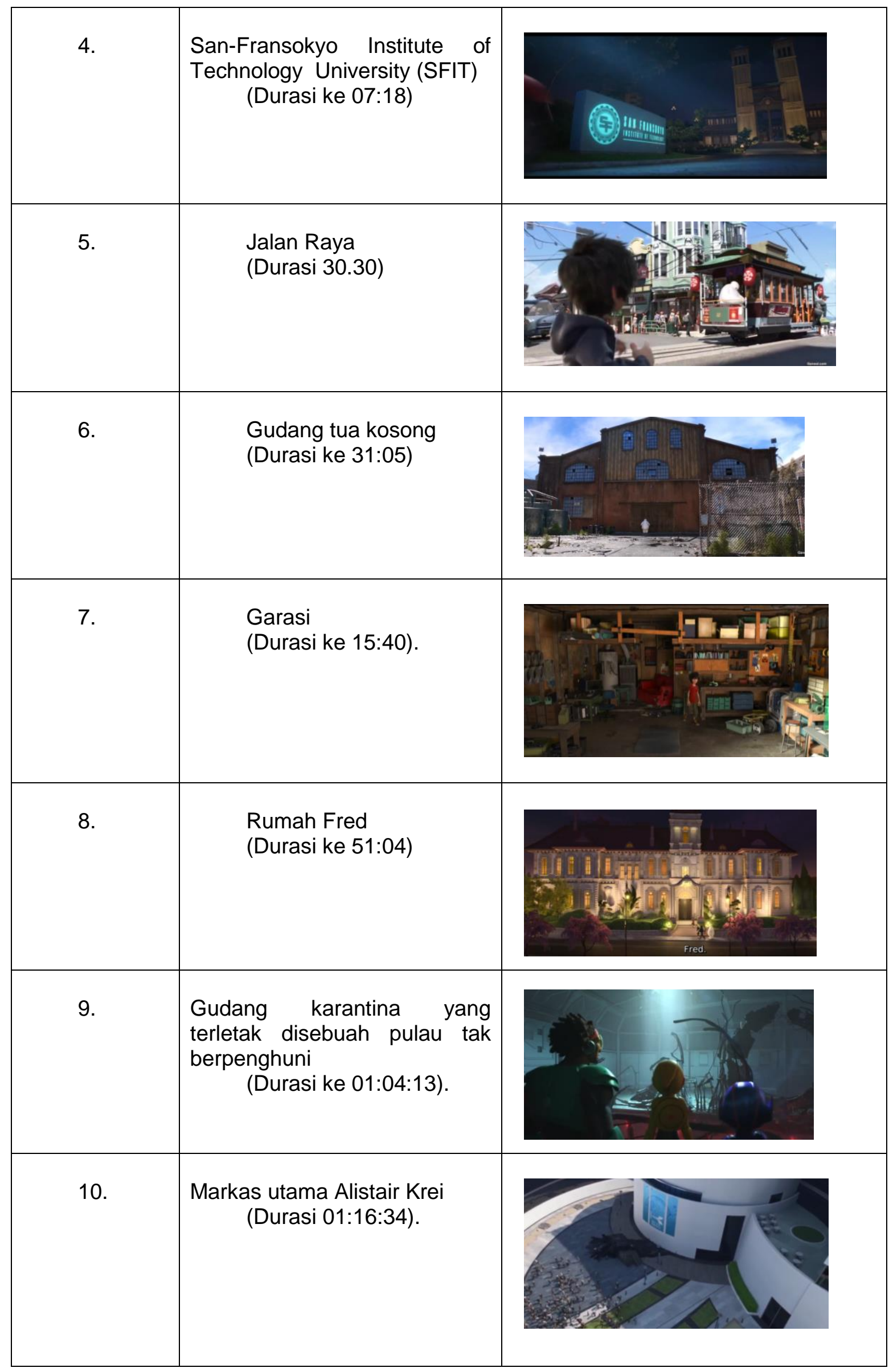


Latar waktu pada film animasi Big Hero 6 ini adalah siang hari ketika sedang berada di jalan raya Hiro mengejar baymax yang berjalan mengikuti microbots yang dibawanya (Durasi ke 30:17), gudang kosong ketika Hiro menemukan bahwa microbots ciaptaannya ternyata telah diproduksi dengan skala besar dan markas Alistair Krei ketika Krei memperkenalkan markas barunya kemudian datanglah Yokai (Durasi ke 33:03), Malam hari ketika tokoh berada di arena pertandingan robot ketika Hiro mengikuti pertarungan robot ilegal (Durasi ke 03:06), rumah Freed ketika Hiro dan teman-temannya dengan basah kuyup diajak ke rumah oleh Fred (Durasi ke 51:04), pelabuhan (Durasi ke 45:28), SFIT (Durasi ke 07:18) dan kantor polisi ketika Bibi Cass menjemput Tadashi dan Hiro yang ternyata tertangkap oleh polisi karena ketahuan telah mengikuti pertandingan robot ilegal (Durasi ke 05:42).

Latar sosial-budaya dalam film animasi Big Hero 6 ini adalah enam superhiro memiliki ciri khas masing-masing dan dari latar kebudayaan yang berbeda, contohnya jenis kulit dan rambut yang berbeda. Tapi mereka tak memasalahkan perbedaan tersebut, mereka tetap saling tolerasi dengan membantu antar sesama dan saling berkerja sama menumpas kejahatan.

Latar susasana dalam film animasi Big Hero 6 ini adalah menyedihkan ketika Tadashi kakak Hiro meninggal (Durasi ke 23:53), Menyenangkan ketika Hiro di terima di San-Fransokyo Institute of Technology University (SFIT) (Durasi ke 21:23), menegangkan ketika Proffesor Callagan mencoba kembali menghidupkan portal teleportasi untuk membalas dendam pada Alistair Krei (Durasi ke 01:17:46) . Mengharukan ketika Hiro kehilangan Baymax dan mencoba kembali membuat Baymax dengan chip kard kesehatan yang dibuat Tadashi dulu (Durasi ke 01:31:06).

e. Sudut Pandang

Sudut padang dalam film animasi Big Hero 6 ini adalah sudut pandang orang ketiga karena dalam hal ini sudut pandang menggunakan kata ganti seperti ia, dia atau nama dari pelaku yang ada dalam cerita yang dibuat oleh penulis atau pengarang.

f. Amanat

Amanat yang terkandung dalm film animasi Big Hero 6 adalah (1) Jadilah orang yang bermanfaat bagi orang lain, (2) jangan mudah putus asa, (3) belajar untuk peduli dengan orang lain karena satu tindakan peduli kita dapat bermanfaat bagi banyak orang lain, (4) pentingnya pendidikan,(5) lihatlah sesuatu dari sudut pandang yang berbeda, (6) jadilah teman yang selalu ada meskipun disaat mengalami kesulitan, (7) balas dendam bukan berarti menyelesaikan masalah.

3. Hasil Analisis Nilai Moral

a). Tolong menolong

Ketika Baymax mendeteksi adanya tanda-tanda kehidupan didalam portal teleportasi kemudian Hiro dan Baymax masuk kedalam portal tersebut dan menemukan Abigail Callagan yang tenggah tertidur panjang di ruang waktu.(Durasi Ke 01:24:35)

Selain itu, Ketika Hiro Hamada sudah tidak mempunyai ide lagi, untuk membuat sebuah penemuan yang akan menjadikan la masuk universitas dimana kakaknya berkuliah, Tadashi Hamada (kakaknya) terus membantu adiknya hingga la mendapatkan ide baru. (Durasi Ke 15:17)

b). Kerja Sama

Ketika keenam superhiro berkerjasama menghentikan Proffesor Callagan yang menyamar menjadi Yokai yang ingin membalas dendam dengan Alistair Krei.(Durasi Ke 01:18:10)

c). Rasa Hormat

Ketika Hiro yang mulai emosi mengetahui bahwa Proffesor Callagan yang telah mencuri microbotnya dan mengetahui bahwa kakaknya Tadashi yang meninggal siasia karena ingin menyelamatkan Proffesor Callagan, kemudian menyuruh Baymax untuk menghancurkan Proffesor Callagan tetapi dicegah Gogo, Wasabi, Fred dan Honey Lemon. (01:10:28)

d). Kebijaksanaan 
Ketika Go go memberikan nasehat kepada Hiro bahwa kita harus menggunakan cara yang benar untuk menghentikan aksi Proffesor Callagan yang menyamar menjadi Yokai (Durasi 01:15:25).

e). Pemberani

Ketika Tadashi yang berani memasuki kampus SIFT untuk menyelamatkan Proffesor Callagan dari kebakaran ( Durasi ke 22:57).

f). Rendah hati

Teman-teman Fred yang baru tahu bahwa Fred merupakan anak orang yang kaya, dalam hal ini membuktikan bahwa Fred adalah orang memiliki sifat rendah hati dan bergaul dengan siapa saja (Durasi Ke 51:31).

g). Pantang menyerah

Tadashi tanpa patah semangat membuat Baymax hingga tes yang ke-84 (Durasi Ke $01: 14: 00)$.

Berdasarkan hasil wawancara yang dilakukan oleh peneliti kepada Bapak Nyono S.Pd., SD selaku guru kelas III SD Negeri Kebonsawahan 02 Juwana bahwa pendidikan karakter merupakan pendidikan yang diterapkan pada peserta didik tentang perilaku, tingkah laku moral atau kelakuan yang dibiasakan pada anak supaya dapat berbuat baik sesuai dengan moral atau aturan. Selain itu Menurut Bapak Nyono, S.Pd.SD film animasi Big Hero 6 merupakan film yang baik ditonton oleh anak sekolah dasar tetapi tetapi masih tetap dalam pengawasan, mengingat film Big Hero 6 juga memiliki nilai positif yang dapat digunakan untuk menumbuhkan sikap kepedulian. film animasi Big Hero 6 juga dapat berperan dalam penanaman nilai karakter kepedulian di sekolah dasar, akan tetapi tetap diberi pengarahan tentang kebaikan agar anak tahu sehingga dapat diteladani dan sisi yang baik agar tidak ditiru.

Berdasarkan observasi yang dilakukan di SD Negeri Kebonsawahan 02 pada tanggal 2 April 2019. Terdapat 15 butir pernyataan yang menyatakan sebagian besar siswa masih memiliki sikap kepedulian seperti siswa mendengarkan guru saat proses pembelajaran hal ini tercermin ketika saat kegiatan pembelajaran berlangsung, saat pemutaran film animasi Big Hero 6 siswa saangat antusias dan memperhatikan dengan cermat. Kemudian saat mengisi angket siswa dapat mengisi dengan baik dan percaya diri sesuai pendapatnya mereka masing-masing. Siswa menghormati teman yang berbeda keyakinan. Siswa membiasakan tolong menolong. Siswa dengan senang hati meminjamkan barang miliknya. Siswa membuang sampah pada tempatnya, sebagian besar siswa sudah melakukannya karena sudah terbiasa di sekolah. Siswa menyiram tanaman di depan kelas. Siswa memulai pembelajaran dengan membaca doa, hal ini di lakukan setiap pagi sebelum pembelajaran dimulai. Siswa melaksanakan kegiatan kebersihan di sekolah, kegiatan piket setiap hari secara bergantian di kelas masing-masing. Namun dalam hal lain masih terdapat siswa yang saling ejek karena hal sepele, siswa masih menertawakan temannya yang mengalami masalah seperti saat temannya ramai sendiri kemudian disuruh maju kedepan oleh guru, masalah yang ditertawakan oleh siswa dalam hal masalah yang disebabkan oleh ulahnya sendiri. Siswa menyapa satu sama lain saat bertemu, hal ini masih dilakukan oleh sebagian kecil siswa, siswa memiliki kelompok bermain sendiri.

Berdasarkan penelitian kepada siswa kelas III SD Negeri Kebonsawahan 02 berupa angket dengan 20 butir pernyataan dengan nilai jawab positif. Siswa kelas III sebanyak 34 siswa. terdapat beberapa poin dan presentase yang termasuk menunjukkan bahwa film animasi Big Hero 6 memiliki pengaruh yang cukup banyak bagi mereka. Hal ini dibuktikan sebanyak 21 dari 34 siswa menyatakan menonton film animasi setiap hari salah satunya film animasi Big Hero 6 yang pernah tayang di beberapa televisi. Sehingga mempermudah peneliti untuk mengulas kembali nilai-nilai karakter dalam film tersebut termasuk sikap kepedulian yang tercermin dalam flm tersebut. Siswa juga merasa setuju bahwa film animasi Big Hero 6 memberikan dampak positif dengan memberikan contoh sikap kepedulian baik di lingkungan maupun sosial. sehingga berpengaruh bagi perilakunya seperti membantu teman yang sedang memerlukan bantuan, meminjami alat tulis kepada teman, menawari dan berbagi makanan, menghormati guru dan staf yang berada di sekolah, mendengarkan guru saat menjelaskan materi, menegur teman yang membuang sampah sembarangan, 
melakukan piket kebersihan kelas sesuai dengan jadwal yang ditentukan, membantu membersihkan papan tulis tanpa diminta guru, mengambil sampah yang ada di bawah meja atau kursi dan tidak suka memetik bunga ditaman untuk mainan, sehingga dalam hal ini film Big Hero 6 dapat dikatakan film yang mendidik yang dapat memberi pengaruh dan memberi pengalaman kepada siswa terhadap pentingnya sikap peduli, hal ini dibuktikan dari hasil angket siswa yang menunjukkan poin-poin yang telah dijabarkan tersebut memiliki presentase yang tinggi yang menunjukkan sebagian besar siswa telah melakukan perilaku tersebut. Tetapi terdapat dua poin yang menunjukkan masih dilakukan sebagian kecil siswa yaitu 11 dari 34 siswa menjawab "Ya" menunjukkan tidak pernah bertengkar dengan teman di kelas dan 23 siswa lainnya menjawab "Tidak" sehingga ini menunjukkan bahwa masih banyak siswa yang sering bertengkar dengan teman di kelas. Selain itu dalam poin "Saya menyisihkan uang jajan untuk bersedekah" menyatakan 14 dari 34 siswa menjawab "Ya" dan 20 dari 34 siswa menyatakan "Tidak" sehingga dalam hal ini menunjukkan bahwa menyisihkan uang jajan untuk bersedekah masih dilakukan oleh sebagian kecil siswa. Selain itu juga dari keseluruhan siswa, sebagian siswa suka mencoret-coret dinding dan meja di kelas dan sebagian lainnya tidak suka mencoret-coret dinding dan meja di kelas.

Hal ini membuktikan bahwa film animasi Big Hero 6 termasuk dalam film animasi yang mendidik dan dapat digunakan sebagai media penanaman nilai karakter kepedulian karena berdasarkan hasil analisis angket tersebut menunjukkan bahwa film tersebut memberi dampak positif bagi siswa seperti tolong menolong kepada teman

\section{Simpulan dan Saran}

Berdasarkan hasil penelitian yang dilakukan dapat disimpulkan bahwa terdapat banyak sikap kepedulian yang tertanam dalam film animasi Big Hero 6. Nilai moral yang terdapat dalam film animasi Big Hero 6 dapat digunakan sebagai contoh teladan dan penanaman sikap kepedulian pada siswa hal ini terbukti dari hasil wawancara, observasi dan hasil analisis angket yang digunakan. Sikap kepedulian tergambar dalam percakapan serta tindakan yang dilakukan oleh para tokoh cerita didalamnya. Nilai-nilai moral yang terkandung dalam fil animasi Big Hero 6 yaitu tolong menolong, kerja sama, rasa hormat, kebijaksanaan, pemberani, rendah hati, dan pantang menyerah. Peran guru dan orang tua juga sangat penting dalam menghimbau pemilihan tayangan televisi yang sesuai dengan usia anak-anak sekolah dasar, karena pada dasarnya anak-anak senang meniru apa yang dilakukan oleh apa yang mereka lihat tanpa mengetahui dampak positif maupun negatifnya. Hanya saja pada film animasi Big Hero 6 menggunakan bahasa Inggris yang menuntun penonton (siswa) untuk memahami bahasanya, namun di dalam film sudah terdapat translate bahasa Indonesia dan tentunya akan membantu pemahaman siswa. Cerita yang disajikan dalam film animasi Big Hero 6 juga menarik, sehingga siswa sangat antusias selama proses penayangan film tersebut.

Berdasarkan simpulan di atas adupun saran yang dapat penliti sampaikan antara lain: 1) Bagi Guru diharapkan dapat lebih kreatif menggunakan media untuk memabantu menananmkan moral pada siswa dan meningkatkan sikap kepedulian siswa, 2) Siwa diharapkan dapat memilih tayang yang sesuai dan mendidik, tidak diharapkan dapat meneladani sikap positif yang tokoh dalam film lakukan,dan tidak meniru perilaku negatif yang tokoh lakukan, 3) Bagi Orangtua diharapkan selalu mengawasi apa yang ditonton oleh anak mereka karena dimasa sekarang banyak tayangan ditelevisi yang tidak mendidik dan tidak untuk ditiru, 4) Bagi penulis film animasi sebaiknya menggunakan pemilihan kata yang sesuai dan tidak terkesan kasar karena film tersebut banyak ditonton oleh semua usia. 


\section{Daftar Pustaka}

Al-Anwari, Amirul Mukminin.2014.Strategi Pembentukan Karakter Peduli Lingkungan Di Sekolah Adiwiyata Mandiri.Jurnal Pendidikan Islam.Vol. XIX, No.02.Jambi: IAIN Sulthan Thahah Saifuddin Jambi.http://jurnal.radenfatah.ac.id/index.php/tadib/article/view/16Diakses pada tanggal 10 Maret 2019

Badarudin. 2018. Peningkatan Sikap Peduli Lingkungan dan Prestasi Belajar IPA menggunakan Model Problem Based Learning Berbasis Literasi pada Subtema Lingkungan Tempat Tinggalku di Kelas IV MI Muhammadiyah Kramat. Jurnal Pendidikan Dasar Indonesia.

Bioskopkeren.xyz.BIG HERO 6-(2014) http://bioskopkeren.xyz/big-hero-6/ Diunduh pada tanggal 25 Oktober 2018

Darmiyati Zuchdi. (2011). Pendidikan Karakter dalam Prespektif. Teori dan Praktek. Yogyakarta: UNY Press

Gusti, A, dkk. (2015). Determinan Intensi Perilaku Pengelolaan Sampah Berkelanjutan pada Siswa Sekolah Dasar. Jurnal Kesehatan Masyarakat

Ghony, Djunaidi \& fauzan almanshur.2017.Metodologi Penelitian Kualitatif.Yogyakarta:ARRUZZ MEDIA

Mahardi, Dedi.2013.The Power Of Care.Jakarta:Percetakan PT Gramedia

Masrukhan, Ahsan. 2016. Pelaksanaan Karakter Peduli Sosial Di SD Negeri Kotagede Yogyakarta. Jurnal Kependidikan Guru Sekolah Dasar Edisi 29 Tahun Ke-5. Yogyakarta: Universitas Negeri Yogyakarta. http://journal.student.uny.ac.id/ojs/index.php/pgsd/article/view/4855. Diakses pada tanggal 12 Maret 2018.

Pramana, K. A. B., Lasmawan, I. W., \& Marhaeni, A. A. I. N. (2014). Pengaruh Penerapan Pembelajaran PQ4R Kontekstual Terhadap Hasil Belajar IPS dan Sikap Peduli Lingkungan Siswa Kelas V. e-Journal Program Pascasarjana Universitas Pendidikan Ganesha, Program Studi Pendidikan Dasar. Volume 4 Tahun 2014.

Sugihartono, Ranang Agung dkk.2010.Animasi Kartun. Kembangan-Jakarta Barat:PT INDEKS Permata Puri Media

Sugiyono.2017.Metode Penelitian Pendidikan.Bandung:Alfabeta

Untari, Mei Fita Asri.2016." Kajian Nilai Moral Dalam Film Kartun Upin Dan Ipin Edisi “IKHLAS DARI HATI" Produksi Les' Copaque”. Jurnal Kependidikan.v olume 6 Nomor 1, 1-9.Semarang:PGSD Universitas PGRI Semarang. 